\title{
Fractionation of silver isotopes in native silver explained by redox reactions
}

\author{
Ryan Mathur ${ }^{\mathrm{a}, *}$, Antonio Arribas ${ }^{\mathrm{b}}$, Peter Megaw ${ }^{\mathrm{c}}$, Marc Wilson ${ }^{\mathrm{d}}$, Steven Stroup ${ }^{\mathrm{a}}$, \\ Danilo Meyer-Arrivillaga ${ }^{a}$, Isabel Arribas ${ }^{e}$ \\ a Juniata College, Huntingdon, PA 16652, USA \\ ${ }^{\mathrm{b}}$ Graduate School of International Resource Sciences, Akita University, Akita 010-8502, Japan \\ ${ }^{\mathrm{c}}$ IMDEX Inc., Tucson, AZ 85728, USA \\ ${ }^{\mathrm{a}}$ Carnegie Museum of Natural History, Pittsburgh, PA 15213, USA \\ ${ }^{\mathrm{e}}$ Mining and Engineering Geology Dept., School of Mining Engineering, Madrid 28003, Spain
}

\begin{abstract}
Scant data exist on the silver isotope composition of native silver specimens because of the relative newness of the technique. This study increases the published dataset by an order of magnitude and presents 80 silver new isotope analyses from native silver originating from a diverse set of worldwide deposits ( 8 deposit types, 33 mining districts in five continents). The measured isotopic range (defined as $\delta^{109} \mathrm{Ag} /{ }^{107} \mathrm{Ag}$ in per mil units compared to NIST $978 \mathrm{Ag}$ isotope standard) is +2.1 to $-0.86 \%$ ( $2 \sigma$ errors less than 0.015 ); with no apparent systematic correlations to date with deposit type or even within districts. Importantly, the data centering on 0\%o all come from high temperature hypogene/primary deposits whereas flanking and overlapping data represent secondary supergene deposits. To investigate the causes for the more fractionated values, several laboratory experiments involving oxidation of silver from natural specimens of Ag-rich sulfides and precipitation and adsorption of silver onto reagent grade $\mathrm{MnO}_{2}$ and $\mathrm{FeOOH}$ were conducted. Simple leach experiments demonstrate little $\mathrm{Ag}$ isotope fractionation occurred through oxidation of $\mathrm{Ag}$ from native $\mathrm{Ag}\left(\Delta_{\text {solution-native }}^{109} \mathrm{Ag}=0.12 \%\right)$. In contrast, significant fractionation occurred through precipitation of native $\mathrm{Ag}$ onto $\mathrm{MnO}_{2}$ (up to $\Delta_{\text {solution- } \mathrm{MnO}}^{109} \mathrm{Ag}=0.68 \%$, or $0.3 \mathrm{amu}$ ). Adsorption of silver onto the $\mathrm{MnO}_{2}$ and $\mathrm{FeOOH}$ did not produce as large fractionation as precipitation (mean value of $\Delta_{\text {solution-MnO2 }}$ ${ }^{109} \mathrm{Ag}=0.10 \%$ o). The most likely cause for the isotopic variations seen relates to redox effects such as the reduction of silver from $\mathrm{Ag}$ (I) to $\mathrm{Ag}^{\circ}$ that occurs during precipitation onto the mineral surface. Since many Ag deposits have halos dominated by $\mathrm{MnO}_{2}$ and $\mathrm{FeOOH}$ phases, potential may exist for the silver isotope composition of ores and surrounding geochemical haloes to be used to better understand ore genesis and potential exploration applications. Aside from the Mn oxides, surface fluid silver isotope compositions might provide information about geochemical reactions relevant to both environmental and hydrometallurgical applications.
\end{abstract}

Keywords: Silver isotopes; Fractionation; Native silver; Ore deposits; $\mathrm{MnO}_{2} ; \mathrm{FeOOH}$

\section{INTRODUCTION}

Silver isotope geochemistry is a relatively new field in

* Corresponding author.

E-mail address: mathurr@juniata.edu (R. Mathur). which the ratio of the two $\mathrm{Ag}$ isotopes $\left({ }^{107} \mathrm{Ag}\right.$ and $\left.{ }^{109} \mathrm{Ag}\right)$ have been used to understand and measure a variety of nat- 
ural and technological processes, such the formation of the solar system (Woodland et al., 2005; Schönbächler et al., 2008), the transformation of environmental nanoparticles (Lu et al., 2016), improving analytical routines in multicollector mass spectrometry (Schönbächler et al., 2007; Yang et al., 2009; Luo et al., 2010), and unraveling the provenance and circulation of past silver coinage (Desaulty et al., 2011). All of these studies found silver isotope variations, but no study has focused on silver ores or the natural processes that might have caused the observed variations. Among other applications, given that silver is a major commodity, understanding the variation of silver isotopes in natural ore deposits may shed light on their ore-forming process, which could enhance exploration and extraction techniques. Further, understanding the silver isotope variations and systematics in natural ores may help explain the variations seen in manufactured materials, in particular those of archaeological and recent historical interest. To address these issues, and explain the silver isotope variations observed, we present silver isotope data of native silver from a diverse set of deposit types coupled with experimental products.

All the primary silver ore deposits on Earth are of hydrothermal origin; i.e., where silver precipitates from an aqueous fluid (at temperatures of $\sim 120$ to $\sim 400^{\circ} \mathrm{C}$; Bodnar et al., 2014) circulating within the Earth's crust as the fluid reacts to a variety of physical and chemical gradients. The principal silver and silver-bearing deposit types include epithermal (low-, intermediate- and highsulfidation), volcanogenic massive sulfides (VMS), sedimentary-exhalative (SEDEX), sediment-hosted $\mathrm{Ag}-\mathrm{Cu}$, carbonate replacement and skarns, porphyry $\mathrm{Cu}$, mesothermal $\mathrm{Ag}-\mathrm{Pb}-\mathrm{Zn}$, and $\mathrm{Ag}-\mathrm{Co}-\mathrm{Ni}-\mathrm{As}$ veins (Fig. 1, Table 1 (Graybeal and Vikre, 2010; Kesler and Simon, 2015).

Most primary silver mineralization in all deposit types occurs as one of four principal mineral groups consisting of hypogene sulfides, sulfosalts, tellurides-selenides, or native silver; silver in the distal parts of some deposits may also occur as a primary species adsorbed on and mixed with manganese oxides. Through weathering and oxidation, the primary (hypogene) species may be transformed into secondary (supergene) minerals such as native silver, silver halides and complex silver-manganese compounds. Notably, native silver can be deposited as both a hypogene and supergene mineral, the latter largely through desulfurization of the silver sulfide acanthite $\left(\mathrm{Ag}_{2} \mathrm{~S}\right)$. Similarly, the complex silver-adsorbed-on-manganese-oxide mixtures can form either as a secondary product or as a primary product where waning hydrothermal conditions overlap with those of the secondary environment (Megaw, 1998). This wide range of silver species and reformulations between primary and secondary phases opens the question of whether or not there is systematic fractionation of the silver isotope composition of species within and between the hypogene and supergene environments. One possibility is that different deposit types, or stages within them, show different silver isotopic values or systematic isotope shifts that can be used to characterize them consistently.

Since the fractionation of most isotopic systems is greater at low temperatures, we expect that greater differences will be observed between high and low temperature (hypogene vs supergene) conditions. Separately, adsorption of silver onto $\mathrm{Mn}$ oxides, as well as other general redox reactions, could lead to a fractionation of silver isotopes independent of temperature. Manganese oxides are common in all deposit types analyzed here and are known to form in both high and low (Sorem and Cameron, 1960; Larson, 1964) temperature environments. This family of minerals has highly charged surfaces which ready adsorb metals like silver (Anderson et al., 1973; McKenzie, 1980; Nicholson, 1992), and the charged surface of Mn oxide minerals is known to cause significant fractionation of isotopes of molybdenum (Arnold et al., 2004; Barling and Anbar, 2004) and copper (Pokrovsky et al., 2008; Bigalke et al., 2009, 2011; Little et al., 2014). By contrast, cadmium does not appear to be fractionated due to surface sorption on Mn oxide (Schmitt et al., 2009; Horner et al., 2010). Finally, electron transfer (redox reactions) occurring during

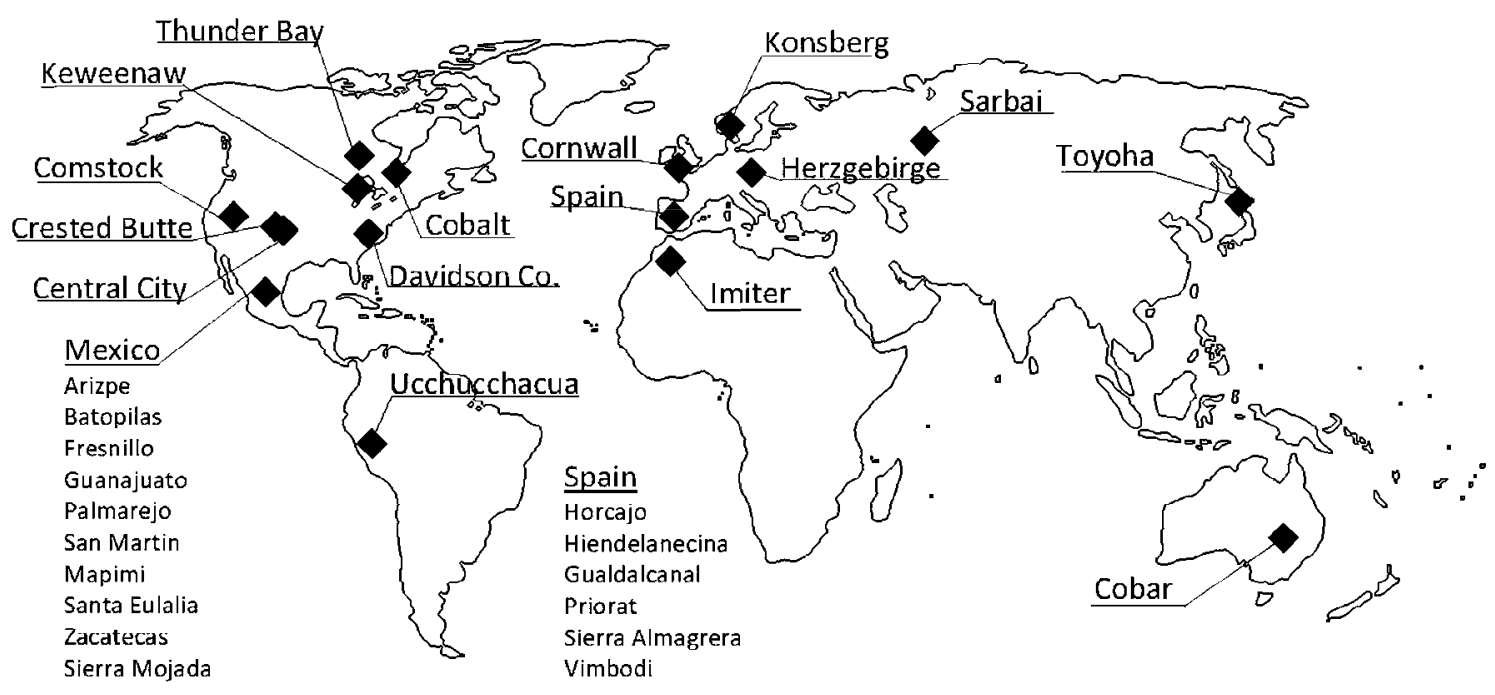

Fig. 1. Location map for deposits where native silver originated. 
Table 1

The Ag isotope composition (in permil) of native silver specimens taken from a variety of locations on earth. The entity that provided the samples is listed in the last column where PKM $=$ Peter Megaw, $\mathrm{CMNH}=$ Carnegie Museum of Natural History, AUM $=$ Akita University Museum, UB = University of Barcelona, BNM = Barcelona Natural Science Museum, MSM = Madrid School of Mines, iCreus $=$ Mr. Joan Abello iCreus.

\begin{tabular}{|c|c|c|c|c|c|c|c|}
\hline Sample ID & Origin & $\delta^{109} \mathrm{Ag}$ & Deposit type & Deposit/mine/orebody & Mining district & $\begin{array}{l}\text { Country (state, } \\
\text { province) }\end{array}$ & Source \\
\hline 31 & Supergene & 0.249 & VMS & Elura Mine & Cobar & Australia (NSW) & PMG \\
\hline 34 & Hypogene & 0.224 & $\mathrm{Ag}-\mathrm{Co}-\mathrm{Ni}-\mathrm{As}$ veins & Cobalt (Christopher Mine) & Timiskaming & Canada $(\mathrm{ON})$ & PMG \\
\hline CM199 & Hypogene & -0.129 & $\mathrm{Ag}-\mathrm{Co}-\mathrm{Ni}-\mathrm{As}$ veins & Cobalt (Violet Mine) & Timiskaming & Canada (ON) & $\mathrm{CMNH}$ \\
\hline CM201 & Hypogene & 0.087 & $\mathrm{Ag}-\mathrm{Co}-\mathrm{Ni}-\mathrm{As}$ veins & Cobalt (Crown Mine) & Timiskaming & Canada (ON) & CMNH \\
\hline CM224 & Hypogene & 0.124 & $\mathrm{Ag}-\mathrm{Co}-\mathrm{Ni}-\mathrm{As}$ veins & Cobalt (Silver Bar Mine) & Timiskaming & Canada (ON) & $\mathrm{CMNH}$ \\
\hline CM226 & Hypogene & 0.072 & $\mathrm{Ag}-\mathrm{Co}-\mathrm{Ni}-\mathrm{As}$ veins & Cobalt (La Rose Mine) & Timiskaming & Canada (ON) & $\mathrm{CMNH}$ \\
\hline CM227 & Hypogene & 0.003 & $\mathrm{Ag}-\mathrm{Co}-\mathrm{Ni}-\mathrm{As}$ veins & McKinley-Darragh Mine & Timiskaming & Canada (ON) & CMNH \\
\hline CM197 & Hypogene & -0.014 & Mesothermal & $\begin{array}{l}\text { Long Tom mine, Port } \\
\text { Arthur }\end{array}$ & Thunder Bay & Canada (ON) & $\mathrm{CMNH}$ \\
\hline CM17621 & Hypogene & -0.143 & Mesothermal & Jachymov & Ertzgebirge & $\begin{array}{l}\text { Czech Republic } \\
\text { (Bohemia) }\end{array}$ & PMG \\
\hline CM204 & Hypogene & -0.053 & Mesothermal & Freiberg & Ertzgebirge & Germany (Saxony) & CMNH \\
\hline AK-238 & Hypogene & 0.032 & IS epithermal & Toyoha & Toyoha & Japan (Hokkaido) & AUM \\
\hline BN-6 & Supergene & 0.130 & VMS & Sarbai mine & Rudny & Kazakhstan (Kostanay) & UB \\
\hline 30 & Supergene & 0.130 & LS epithermal & El Tigre & Arizpe & Mexico (Sonora) & PMG \\
\hline 26 & Hypogene & 0.162 & $\mathrm{Ag}-\mathrm{Co}-\mathrm{Ni}-\mathrm{As}$ veins & New Nevada & Batopilas & Mexico (Chihuahua) & PMG \\
\hline CM191 & Hypogene & 0.065 & IS epithermal & Batopilas & Batopilas & Mexico (Chihuahua) & $\mathrm{CMNH}$ \\
\hline CM207 & Hypogene & -0.057 & IS epithermal & Batopilas & Batopilas & Mexico (Chihuahua) & CMNH \\
\hline 33 & Hypogene & 0.368 & IS epithermal & Proaño (Veta San Carlos) & Fresnillo & Mexico (Zacatecas) & PMG \\
\hline $8 \mathrm{ag}$ & Uncertain & 0.024 & IS epithermal & Proaño & Fresnillo & Mexico (Zacatecas) & PMG \\
\hline 37 & Supergene & 0.548 & IS epithermal & Veta Madre (Rayas) & Guanajuato & Mexico (Guanajuato) & PMG \\
\hline $\mathrm{BN}-7$ & Supergene & 0.180 & IS epithermal & Veta Madre (Rayas) & Guanajuato & Mexico (Guanajuato) & UB \\
\hline $\mathrm{BN}-7$ & Supergene & 0.292 & IS epithermal & Veta Madre (Rayas) & Guanajuato & Mexico (Guanajuato) & UB \\
\hline CM13129 & Uncertain & 0.152 & IS epithermal & Guanajuato & Guanajuato & Mexico (Guanajuato) & PMG \\
\hline 42 & Hypogene & 0.238 & $\begin{array}{l}\text { Carbonate } \\
\text { replacement }\end{array}$ & Ojuela & Mapimí & Mexico (Durango) & PMG \\
\hline MGB - 1406 & Supergene & 0.019 & IS epithermal & Ojuela & Mapimí & Mexico (Durango) & $\mathrm{BNM}$ \\
\hline 38 & Supergene & 0.311 & IS epithermal & Palmarejo & Palmarejo & Mexico (Chihuahua) & PMG \\
\hline 35 & Hypogene & 0.163 & Skarn & San Martin & San Martin & Mexico (Zacatecas) & PMG \\
\hline 10 & Supergene & 0.789 & $\begin{array}{l}\text { Carbonate } \\
\text { replacement }\end{array}$ & Mina Vieja/Buena Tierra & Santa Eulalia & Mexico (Chihuahua) & PMG \\
\hline 36 & Hypogene & 0.148 & $\begin{array}{l}\text { Carbonate } \\
\text { replacement }\end{array}$ & Potosi (Tunel) & Santa Eulalia & Mexico (Chihuahua) & PMG \\
\hline 29 & Supergene & 0.150 & $\begin{array}{l}\text { Carbonate } \\
\text { replacement }\end{array}$ & Veta Rica & Sierra Mojada & Mexico (Coahuila) & PMG \\
\hline 32 & Supergene & -0.081 & IS epithermal & Veta Grande & Zacatecas & Mexico (Zacatecas) & PMG \\
\hline CM12302 & Hypogene & 0.076 & IS epithermal & Zacatecas & Zacatecas & Mexico (Zacatecas) & PMG \\
\hline CM189 & Hypogene & 0.079 & IS epithermal & Zacatecas & Zacatecas & Mexico (Zacatecas) & $\mathrm{CMNH}$ \\
\hline CM190 & Hypogene & 0.046 & IS epithermal & Zacatecas & Zacatecas & Mexico (Zacatecas) & $\mathrm{CMNH}$ \\
\hline CM193 & Hypogene & 0.024 & IS epithermal & Zacatecas & Zacatecas & Mexico (Zacatecas) & $\mathrm{CMNH}$ \\
\hline CM194 & Hypogene & 0.043 & IS epithermal & Zacatecas & Zacatecas & Mexico (Zacatecas) & $\mathrm{CMNH}$ \\
\hline $\mathrm{BN}-11$ & Supergene & -0.864 & Mesothermal & Imiter & Imiter & Morocco (Ouarzazate) & UB \\
\hline Imiter & Hypogene & -0.309 & Mesothermal & Imiter & Imiter & Morocco (Ouarzazate) & AUM \\
\hline MO-2 & Hypogene & 0.065 & Mesothermal & Imiter & Imiter & Morocco (Ouarzazate) & $\mathrm{CMNH}$ \\
\hline $\mathrm{MO}-3$ & Hypogene & 0.079 & Mesothermal & Imiter & Imiter & Morocco (Ouarzazate) & $\mathrm{CMNH}$ \\
\hline $\mathrm{MO}-4$ & Hypogene & 0.061 & Mesothermal & Imiter & Imiter & Morocco (Ouarzazate) & $\mathrm{CMNH}$ \\
\hline $\mathrm{MO}-5$ & Hypogene & 0.057 & Mesothermal & Imiter & Imiter & Morocco (Ouarzazate) & $\mathrm{CMNH}$ \\
\hline 25 & Hypogene & 0.247 & $\mathrm{Ag}-\mathrm{Co}-\mathrm{Ni}-\mathrm{As}$ veins & Kongsberg & Kongsberg & Norway (Buskerud) & PMG \\
\hline BN-9 & Supergene & -0.294 & $\mathrm{Ag}-\mathrm{Co}-\mathrm{Ni}-\mathrm{As}$ veins & Kongsberg & Kongsberg & Norway (Buskerud) & UB \\
\hline CM186 & Hypogene & -0.007 & $\mathrm{Ag}-\mathrm{Co}-\mathrm{Ni}-\mathrm{As}$ veins & Kongsberg & Kongsberg & Norway (Buskerud) & CMNH \\
\hline P-2 & Hypogene & -0.052 & IS epithermal & Ucchucchacua & Ucchucchacua & Peru (Lima) & CMNH \\
\hline P-3 & Hypogene & -0.038 & IS epithermal & Ucchucchacua & Uechucchacua & Peru (Lima) & $\mathrm{CMNH}$ \\
\hline P-5 & Hypogene & -0.016 & IS epithermal & Ucchucchacua & Ucchucchacua & Peru (Lima) & $\mathrm{CMNH}$ \\
\hline MGB - 4160 & Supergene & 0.159 & Mesothermal & El Horcajo & El Horcajo & Spain (Ciudad Real) & BNM \\
\hline
\end{tabular}


Table 1 (continued)

\begin{tabular}{|c|c|c|c|c|c|c|c|}
\hline Sample ID & Origin & $\delta^{109} \mathrm{Ag}$ & Deposit type & Deposit/mine/orebody & Mining district & $\begin{array}{l}\text { Country (state, } \\
\text { province) }\end{array}$ & Source \\
\hline $\begin{array}{l}\text { MGB - } \\
14091\end{array}$ & Hypogene & 0.002 & Mesothermal & Guadalcanal & Guadalcanal & Spain (Seville) & BNM \\
\hline 5245 & Hypogene & -0.021 & Mesothermal & Mina San Carlos & Hiendelaencina & Spain (Guadalajara) & MSM \\
\hline Nat Ag & Supergene & 2.142 & Mesothermal & Hiendelaencina & Hiendelaencina & Spain (Guadalajara) & MSM \\
\hline $\mathrm{BN}-1$ & Hypogene & -0.012 & Mesothermal & Balcoll-Falset & Priorat & Spain (Tarragona) & $\mathrm{UB}$ \\
\hline $\mathrm{BN}-3$ & Hypogene & 0.040 & Mesothermal & Balcoll-Falset & Priorat & Spain (Tarragona) & UB \\
\hline $\mathrm{BN}-8$ & Hypogene & -0.103 & Mesothermal & Balcoll-Falset & Priorat & Spain (Tarragona) & $\mathrm{UB}$ \\
\hline JAC-1 & Hypogene & 0.021 & Mesothermal & Balcoll-Falset & Priorat & Spain (Tarragona) & iCreus \\
\hline JAC-2 & Hypogene & 0.014 & Mesothermal & Balcoll-Falset & Priorat & Spain (Tarragona) & iCreus \\
\hline $\begin{array}{l}\text { JAC-2 } \\
\text { (wire 1) }\end{array}$ & Hypogene & -0.177 & Mesothermal & Balcoll-Falset & Priorat & Spain (Tarragona) & iCreus \\
\hline $\begin{array}{l}\text { JAC-2 } \\
\text { (wire 2) }\end{array}$ & Hypogene & -0.148 & Mesothermal & Balcoll-Falset & Priorat & Spain (Tarragona) & iCreus \\
\hline $\begin{array}{l}\text { JAC-2 } \\
\text { (wire 3) }\end{array}$ & Hypogene & -0.257 & Mesothermal & Balcoll-Falset & Priorat & Spain (Tarragona) & iCreus \\
\hline $\begin{array}{l}\text { JAC-2 } \\
\text { (wire 4) }\end{array}$ & Hypogene & -0.095 & Mesothermal & Balcoll-Falset & Priorat & Spain (Tarragona) & iCreus \\
\hline $\begin{array}{l}\text { JAC-2 } \\
\text { (wire 5) }\end{array}$ & Hypogene & -0.148 & Mesothermal & Balcoll-Falset & Priorat & Spain (Tarragona) & iCreus \\
\hline $\begin{array}{l}\text { JAC-2 } \\
\text { (wire 6) }\end{array}$ & Hypogene & -0.208 & Mesothermal & Balcoll-Falset & Priorat & Spain (Tarragona) & iCreus \\
\hline JAC-3 & Supergene & 0.075 & Mesothermal & Balcoll-Falset & Priorat & Spain (Tarragona) & iCreus \\
\hline 16 & Supergene & -0.335 & IS epithermal & Las Herrerías (S. Matilde) & $\begin{array}{l}\text { Sierra } \\
\text { Almagrera }\end{array}$ & Spain (Almeria) & MSM \\
\hline 623 & Supergene & -0.226 & IS epithermal & Las Herrerías & $\begin{array}{l}\text { Sierra } \\
\text { Almagrera }\end{array}$ & Spain (Almeria) & MSM \\
\hline 881 & Supergene & -0.305 & IS epithermal & Las Herrerías & $\begin{array}{l}\text { Sierra } \\
\text { Almagrera }\end{array}$ & Spain (Almeria) & MSM \\
\hline $\mathrm{BN}-2$ & Supergene & -0.134 & IS epithermal & Las Herrerias & $\begin{array}{l}\text { Sierra } \\
\text { Almagrera }\end{array}$ & Spain (Almeria) & $\mathrm{UB}$ \\
\hline MGB - 5136 & Hypogene & 0.014 & Mesothermal & Mina Atrevida & Vimbodí & Spain (Tarragona) & $\mathrm{BNM}$ \\
\hline CM188 & Hypogene & 0.164 & Mesothermal & Cornwall & Cornwall & UK (Cornwall) & $\mathrm{CMNH}$ \\
\hline CM215 & Hypogene & -0.007 & LS epithermal & Central City & Central City & USA (Colorado) & $\mathrm{CMNH}$ \\
\hline CM206 & Hypogene & -0.009 & LS epithermal & Central City & Central City & USA (Colorado) & $\mathrm{CMNH}$ \\
\hline CM212 & Supergene & 0.429 & IS epithermal & Consolidated Virginia & Comstock & USA (Nevada) & $\mathrm{CMNH}$ \\
\hline CM221 & Hypogene & -0.142 & IS epithermal & Sylvanite Mine & Crested Butte & USA (Colorado) & $\mathrm{CMNH}$ \\
\hline CM220 & Hypogene & 0.216 & LS epithermal & Cripple Creek & Cripple Creek & USA (Colorado) & $\mathrm{CMNH}$ \\
\hline CM211 & Hypogene & -0.057 & IS epithermal & King's Mine & Davidson Co. & USA (North Carolina) & CMNH \\
\hline $\mathrm{BN}-4$ & Supergene & -0.130 & $\begin{array}{l}\text { Sediment-hosted } \\
\mathrm{Cu}-\mathrm{Ag}\end{array}$ & South Kearsarge & Keweenaw & USA (Michigan) & UB \\
\hline M-1 & Supergene & -0.153 & $\begin{array}{l}\text { Sediment-hosted } \\
\mathrm{Cu}-\mathrm{Ag}\end{array}$ & Calumet \& Hecla & Keweenaw & USA (Michigan) & CMNH \\
\hline M-2 & Supergene & -0.142 & $\begin{array}{l}\text { Sediment-hosted } \\
\mathrm{Cu}-\mathrm{Ag}\end{array}$ & Calumet \& Hecla & Keweenaw & USA (Michigan) & $\mathrm{CMNH}$ \\
\hline M-3 & Supergene & -0.142 & $\begin{array}{l}\text { Sediment-hosted } \\
\mathrm{Cu}-\mathrm{Ag}\end{array}$ & Calumet \& Hecla & Keweenaw & USA (Michigan) & $\mathrm{CMNH}$ \\
\hline M-4 & Supergene & -0.194 & $\begin{array}{l}\text { Sediment-hosted } \\
\mathrm{Cu}-\mathrm{Ag}\end{array}$ & Calumet \& Hecla & Keweenaw & USA (Michigan) & $\mathrm{CMNH}$ \\
\hline M-5 & Supergene & 0.091 & $\begin{array}{l}\text { Sediment-hosted } \\
\mathrm{Cu}-\mathrm{Ag}\end{array}$ & Calumet \& Hecla & Keweenaw & USA (Michigan) & $\mathrm{CMNH}$ \\
\hline
\end{tabular}

Table 2

The results from leach experiments of native silver and $\mathrm{Ag}_{2} \mathrm{~S}$. Ag isotope data are from the leach solution (aq), starting mineral before leaching ( $\mathrm{min}$ ), and residual mineral after leaching (res $\mathrm{min}$ ). Fractionation factor $\alpha$ and delta $\Delta$ are defined in the text where aq $=\mathrm{aqueous} A \mathrm{~g}$ isotope composition and $\mathrm{min}=$ mineral $\mathrm{Ag}$ isotope composition.

\begin{tabular}{lllllll}
\hline Sample & $\mathrm{Ag}(\mathrm{ppm})$ & $\delta^{109} \mathrm{Ag} \%_{\text {min }}$ & $\delta^{109} \mathrm{Ag} \%_{o_{\text {aq }}}$ & $\delta^{109} \mathrm{Ag} \%_{o_{\text {res min }}}$ & $\alpha_{\text {aq-min }}$ & $\Delta_{\text {sol- min }}$ \\
\hline Native Ag leach & 6200 & 0.15 & 0.260 & 0.14 & 1.0001 & 0.120 \\
$\mathrm{Ag} \mathrm{g}_{2}$ leach & 1030 & -0.03 & -0.030 & -0.03 & 1.0000 & 0.000 \\
\hline
\end{tabular}


Table 3

The results from the adsorption and precipitation experiment where native Ag precipitated on the surface of the $\mathrm{MnO}$ surface. $\mathrm{pH}$ monitored throughout the experiment fractionation factors and delta values explained in text.

\begin{tabular}{|c|c|c|c|c|c|c|c|c|c|c|}
\hline Phase & Reaction & $\mathrm{pH}$ & Sample & $\mathrm{Ag}$ (ppm) & $\mathrm{Ag} \% \mathrm{ads}$ & $\delta^{109} \mathrm{Ag} \%_{\text {starting }}$ & $\delta^{109} \mathrm{Ag} \% o_{\mathrm{aq}}$ & $\delta^{109} \mathrm{Ag}_{\min } \%$ & $\alpha_{\mathrm{aq}-\mathrm{MnO}}$ & $\Lambda_{\text {sol-Mno }}$ \\
\hline $\mathrm{MnO} 2$ & $\mathrm{Ads}+\mathrm{Ppt}$ & 4 & Ads & 20.7 & $17 \%$ & 0 & 0.060 & -0.133 & 1.00019 & 0.193 \\
\hline $\mathrm{MnO} 2$ & $\mathrm{Ads}+\mathrm{Ppt}$ & 5 & Ads & 10.4 & $58 \%$ & 0 & 0.222 & -0.118 & 1.00034 & 0.340 \\
\hline $\mathrm{MnO} 2$ & $\mathrm{Ads}+\mathrm{Ppt}$ & 6 & Ads & 5.7 & $77 \%$ & 0 & 0.289 & -0.068 & 1.00036 & 0.357 \\
\hline $\mathrm{MnO} 2$ & $\mathrm{Ads}+\mathrm{Ppt}$ & 7 & Ads & 2.9 & $88 \%$ & 0 & 0.299 & -0.032 & 1.00033 & 0.331 \\
\hline $\mathrm{MnO} 2$ & $\mathrm{Ads}+\mathrm{Ppt}$ & 9 & Ads & 2.3 & $91 \%$ & 0 & 0.640 & -0.053 & 1.00069 & 0.693 \\
\hline
\end{tabular}

dissolution and precipitation of metal-rich phases, for example iron and copper (Anbar et al., 2000; Schauble et al., 2001; Skulan et al., 2002; Poulson et al., 2005; Jang et al., 2008; Black et al., 2010) cause significant fractionation. To constrain these mechanisms, this contribution presents experimental data to observe how redox and adsorption chemistry fractionate silver.

\section{MATERIAL ANALYZED AND EXPERIMENTAL DESIGN}

In addition to analytical measurements of dissolved hypogene and supergene native silver from natural deposits, two laboratory experiments, leach and precipitation and sorption onto $\mathrm{MnO}_{2}$ and $\mathrm{FeOOH}$, were designed to determine how silver isotope fractionation might occur in natural systems. In the leach experiments, silver is oxidized from native silver and in some of the adsorption experiments silver is reduced from solution into/onto $\mathrm{Mn}$ oxide or FeOOH. Due to the precipitation of $\mathrm{Ag}$ onto the mineral surfaces in the adsorption experiments, another set of experiments was conducted that inhibited precipitation in order to observe fractionation exclusively induced by adsorption.

\subsection{Native silver samples from silver deposits}

The specimens of native silver used in this study were collected by the authors from their own mineral collections, collections at several museums (including the Carnegie Museum of Natural History, the Madrid School of Mines, the University of Barcelona and Barcelona Museum of Natural Sciences, the Akita University Museum) and samples provided by Mr. Joan Abello i Creus (Table 1). The samples are from 45 different individual mines or mineral deposits located in 33 silver mining districts in 5 continents; they are representative of eight different silver deposit types in nature (out of a total of ten (Fig. 1)).

Small mineral fragments ranging in mass from 0.02 to $0.14 \mathrm{~g}$ were placed in a $15 \mathrm{ml}$ Teflon jar with $5 \mathrm{ml}$ of 15 $\mathrm{M} \mathrm{HNO}_{3}$ and heated to $120^{\circ} \mathrm{C}$ overnight. Complete dissolution was confirmed visually. The solution was diluted and approximately $10 \mu \mathrm{g}$ of $\mathrm{Ag}$ was used to ion exchange chromatography described below.

\subsection{Leach experiments}

The partial dissolution of native silver and a silver sulfide $\left(\mathrm{Ag}_{2} \mathrm{~S}\right)$ was done with dilute nitric acid. A small fragment of the mineral was digested and used to obtain the initial silver isotope composition. The mass of both the native silver $(0.07 \mathrm{~g})$ and $\mathrm{Ag}_{2} \mathrm{~S}(0.05 \mathrm{~g})$ were recorded and phases were placed in a $15 \mathrm{ml}$ Teflon jar containing $10 \mathrm{ml}$ of $2 \mathrm{M}$ ultrapure $\mathrm{HNO}_{3}$. The silver phases were leached for $18 \mathrm{~h}$ and the residual phases were washed with MQ (18 $\Omega$ ) and dried. Solutions and solids were kept for isotope analysis and the silver concentrations in solutions were measured on an ICP-OES at the Pennsylvania State University (Table 2). The redox state of silver in the reactions monitored here are $\mathrm{Ag}^{\circ} \rightarrow \operatorname{Ag}(\mathrm{I})$ in the dissolution of native silver and $\mathrm{Ag}(\mathrm{I})_{2} \mathrm{~S} \rightarrow \mathrm{Ag}(\mathrm{I})$. Thus, there are cases where oxidation occurred and did not occur. The surfaces of the residual silver phases after leaching were examined with an SEM to detect the presence of extraneous phases or mixtures.

\subsection{Precipitation and sorption of silver onto $\mathrm{MnO}_{2}$ and $\mathrm{FeOOH}$}

These experiments were conducted with pure synthetic minerals in silver-rich solutions. Two different experiments were designed to monitor the isotopic variations caused by precipitation and adsorption. Since silver is a photo sensitive element, it can precipitate from solution due to exposure to light. Thus, the experiments were conducted in light, which enhanced the ability to precipitate native silver from solution along with adsorption (ADS + PPT in Table 3), and in dark conditions, to suppress the precipitation of silver and allow only adsorption (ADS in Table 4). SEM imaging of the mineral phases following exposure to the fluid confirmed the precipitation and adsorption of silver onto the surface of the materials of interest.

The solutions were made by adding small amounts of silver isotope standard NIST 978 to MQ water (NIST 978, is the reference standard for all silver isotopic analyses). Since the silver standards are stored in $1.5 \mathrm{M} \mathrm{HNO}_{3}$, the resulting solutions have $\mathrm{pH}$ of less than 2 . Therefore, the $\mathrm{pH}$ of the solutions was adjusted to a $3 \mathrm{M} \mathrm{NaOH}$ solution (Sigma Gamma Aldrich) and monitored before and after the experiment. $0.02 \mathrm{~g}$ of mineral were added to $100 \mathrm{ml}$ flasks which contained $40 \mathrm{ml}$ of Ag-rich solutions (at $25 \mathrm{ppm}$ for the ADS + PPT and $30 \mathrm{ppm} \mathrm{Ag} \mathrm{for} \mathrm{the} \mathrm{ADS).} \mathrm{Five} \mathrm{different}$ $\mathrm{pH}$ levels were monitored in 5 different flasks at $\mathrm{pHs}$ of 4 , $5,6,7$, and 9 (labeled by $\mathrm{pH}$ in Tables 2 and 3). The amount of solution was measured gravimetrically throughout the process as aliquots were removed for isotopic analysis. The starting and ending silver concentrations of the 


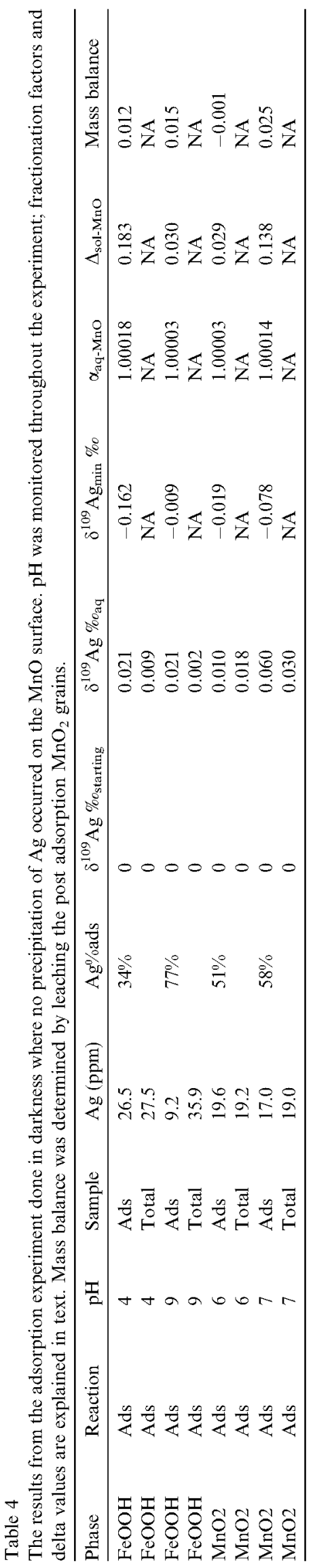

solutions were measured on the ICP-OES at the Pennsylvania State University.

After the minerals were added, the solutions were put in a shaker to ensure the fine mineral particles interacted with the solution. For the ADS + PPT experiments, the procedure was conducted in a well-lit room and set in the shaker for $12 \mathrm{~h}$. For the ADS experiments, the minerals and solution were combined in a dark room and the experiments were covered with aluminum foil and shaken for $3 \mathrm{~h}$. After shaking, the experiments were centrifuged and solutions were filtered and decanted for the concentration and isotope analyses.

The amount and isotopic composition of silver on the surface of the minerals was constrained two different ways for each experiment. For the ADS + PPT experiments, the amount of silver on the surface of the minerals was calculated by taking the total mass of silver in the starting solutions and subtracting the mass remaining in the liquid after completion of the experiment. The isotopic composition of silver on the mineral surface was constrained mathematically. For the ADS experiments, a $10 \mathrm{ml}$ aliquot was removed for silver isotope analysis. Nitric acid was then added to the remaining solution with $\mathrm{MnO}_{2}$ to drop the $\mathrm{pH}<1$ and the concentration and isotopic composition was measured in this solution. The concentration and isotopic composition of the leach solution was used to constrain the silver on the mineral surface.

The experiments were conducted in duplicate so that the mineral grains could be studied in the SEM and the solutions could be studied for isotope and concentration analysis. At the termination of the experiment, the $\mathrm{MnO}_{2}$ in solution was centrifuged into mineral pellets at the base of the centrifuge tubes. Solutions were decanted and filtered for concentration and isotope work. The residual $\mathrm{MnO}_{2}$ material was dried and imaged using SEM with EDS at Juniata College. The $\mathrm{MnO}_{2}$ was gently poured onto carbon tape which was then carbon coated for analysis on the SEM.

Mass balance was calculated in two different ways. For the ADS + PPT experiments, the adsorbed silver isotope composition was calculated by knowledge of the silver isotope composition of the starting solutions and the silver isotope composition of the ending solution. For the ADS experiments, the silver isotope composition of the acidic solution was measured and used to calculate the silver on the mineral surface and this value was then used to calculate mass balance. Mass balance equations for both approaches are explained below.

\section{ANALYTICAL METHODS}

\subsection{Element concentration in solution}

The concentration of silver and ions for the chromatography calibration were measured on an ICP-OES at the Pennsylvania State University. Aliquots from each solution were diluted in $0.3 \mathrm{~N} \mathrm{HNO}_{3}$ for analysis. Concentrations were determined with standard calibration curves that ranged from 0.6 to $10 \mathrm{ppm}$ with indium used as an internal standard. 


\subsection{Silver isotope analyses}

Sample preparation varied slightly for the type of chemical matrix before entering the Neptune ICP-MS multicollector at Pennsylvania State University. Previous work on complex chemical matrices indicates that a two or three stage ion exchange chromatography is required for consistent results (Woodland et al., 2005; Schönbächler et al., 2007; Yang et al., 2009; Luo et al., 2010). In contrast, Chugaev and Chernyshev (2012) demonstrated that Ag from measurements from native gold specimens did not require chromatography. Given that the chemical matrices of the solutions and solids are predominantly silver rich but do contain other ions, we utilized the first step of the ion exchange chromatography outlined in Luo et al. (2010). $1.25 \mathrm{ml}$ of wet Biorad anion exchange resin AG1-X8, 100-200 mesh, chloride form poured into $10 \mathrm{ml}$ Biorad spin columns were used. Successive rinses of dilute $\mathrm{HCl}$ cleaned the unwanted ions from samples and the silver was collected in $50 \mathrm{ml}$ of $1 \mathrm{M} \mathrm{HNO}_{3}$. A column calibration was conducted on dried salts from a synthetic solution containing $200 \mu \mathrm{g}$ of each of the following elements $\mathrm{Si}, \mathrm{Mn}, \mathrm{Zr}$, $\mathrm{Mg}, \mathrm{Ca}, \mathrm{K}, \mathrm{Na}, \mathrm{Fe}, \mathrm{Cu}, \mathrm{Zn}, \mathrm{Cd}$ and $20 \mu \mathrm{g}$ of silver. The calibration confirmed silver was the only element remaining above blank level in the last $50 \mathrm{ml}$ collection of $1 \mathrm{M} \mathrm{HNO}_{3}$.

The total amount of silver in solutions containing $\mathrm{Cl}$ - is limited by the solubility product of $\mathrm{AgCl}$, where the $\mathrm{Ksp}=10^{-10.48}$ (Drever, 1988). Given that the normality of dilute $\mathrm{HCl}$ loaded onto the column is $50 \mathrm{ml}$ at $0.5 \mathrm{M}$, the total activity of $\mathrm{Cl}$ - in solution limits the amount of silver that could potentially dissolve into solution. Approximately $20 \mu \mathrm{g}$ of silver in the salts is the maximum amount of silver that will dissolve. Since the activity of silver is controlled by the ionic strength of the solution, the presence of other ions in solution increases the amount of $\mathrm{Ag}$ that will be dissolved.

To test this relationship, we dried down aliquots of NIST 978 standard solutions so that 20,40,100,400 and $600 \mu \mathrm{g}$ silver remained in the dried salts. The dried salts were used in the ion exchange chromatography described above and all columns yielded 20 total micrograms of silver. As seen in Fig. 2A, if there is excess silver in the salt, not all of the mass is recovered and the isotope composition of the standard does not remain constant with the undissolved $\mathrm{AgCl}$ species acquiring the lighter silver isotope. Therefore, this experimentation suggests no greater than $40 \mu \mathrm{g}$ should be used for the chromatographic separation described here.

Solutions were entered into the Neptune ICP-MS at 150 ppb which generated a 2-3 V signal for ${ }^{107} \mathrm{Ag}$. Samples were aspirated into a wet plasma while the instrument is in lowresolution mode (Schönbächler et al., 2007). Collectors were set up in a similar fashion to Luo et al. (2010) where ${ }^{106} \mathrm{Pd}$ is in $\mathrm{L} 1,{ }^{107} \mathrm{Ag}$ in is the axial position, ${ }^{108} \mathrm{Pd}$ is in $\mathrm{H} 1$ and ${ }^{109} \mathrm{Ag}$ is in $\mathrm{H} 2$. As mentioned in previous works (Carlson and Hauri, 2001; Lu et al., 2016; Ek et al., 2017), the addition of palladium to correct for the mass bias of the instrument is the most robust means to correct the data. Thus, the samples were doped with $100 \mathrm{ppb}$ of palladium ICP-MS standard from High Purity standards traceable to NIST SRM3138. Samples were corrected with palladium and then bracketed in traditional standardsample-standard bracketing.

The presence of $\mathrm{Zr}$ in the solutions could cause an interference on the $\mathrm{Pd}$ masses due to $\mathrm{Zr}$-oxide formation and cause issues with using $\mathrm{Pd}$ to correct for Ag mass bias as pointed by Ek et al. (2017). As seen in supplemental Fig. 1, the presence of trace $\mathrm{Zr}$ causes the standard to produce highly fractionated values $(+3$ to +20 per mil), greater than values reported here. Equally important, the instrument required thirty-minute rinse times for the standard to return to acceptable ranges. The data reported here did not show any variation of the NIST 3138 standard beyond the reported $0.015 \%$. $\mathrm{Zr}$ oxide interference on the Pd used to correct mass bias did not cause fractionation in the measurements. The data are robust because the sample matrix possessed no $\mathrm{Zr}$ (native $\mathrm{Ag}$ contains $\%$ level $\mathrm{Ag}$ and at best ppm level Zr), the standards remained constant throughout
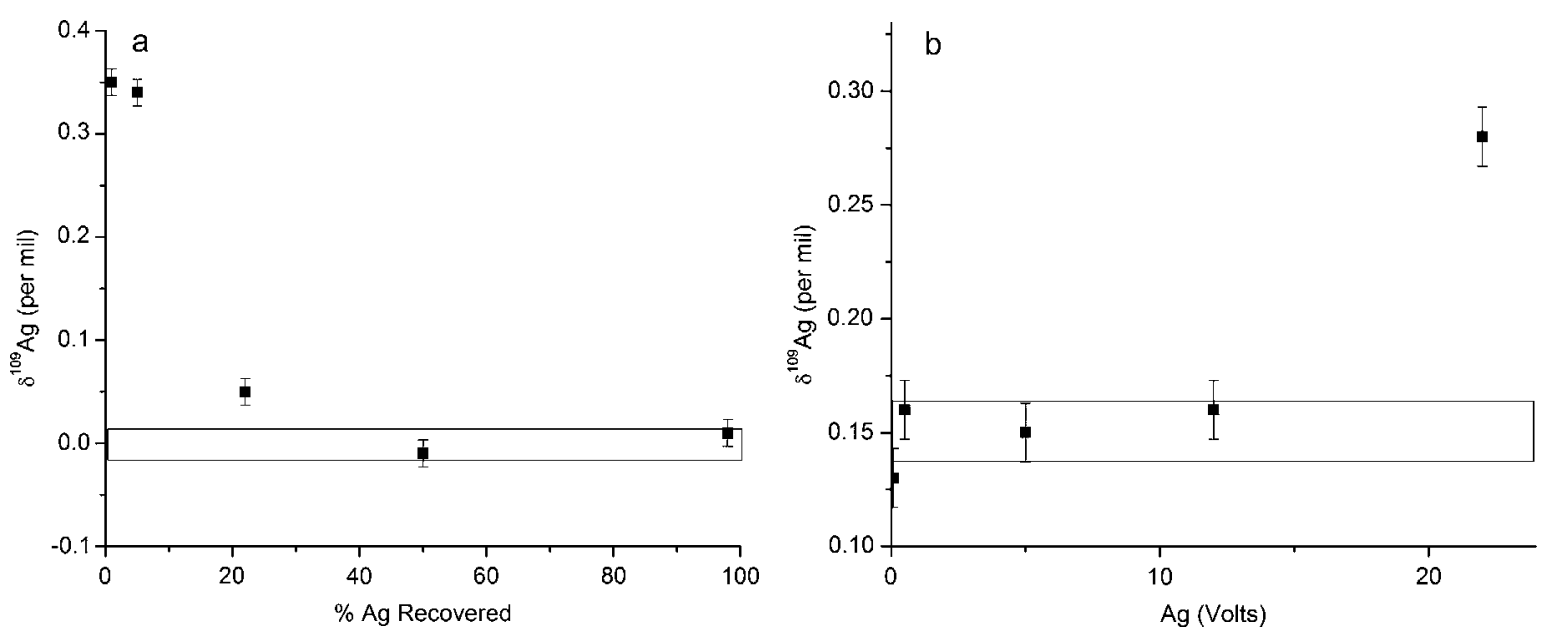

Fig. 2. These figures relate to the chemical processing and measurements of silver on the ICP-MS multicollector where (A) Gray bar indicates the NIST 978 standard and how recovery of Ag from solution can cause isotopic differences. (B) Compares how changes in voltage relative to the $3 \mathrm{~V}$ standard for sample CM188. Note voltages less than 1 or greater than 10 did not produce repeatable results. 


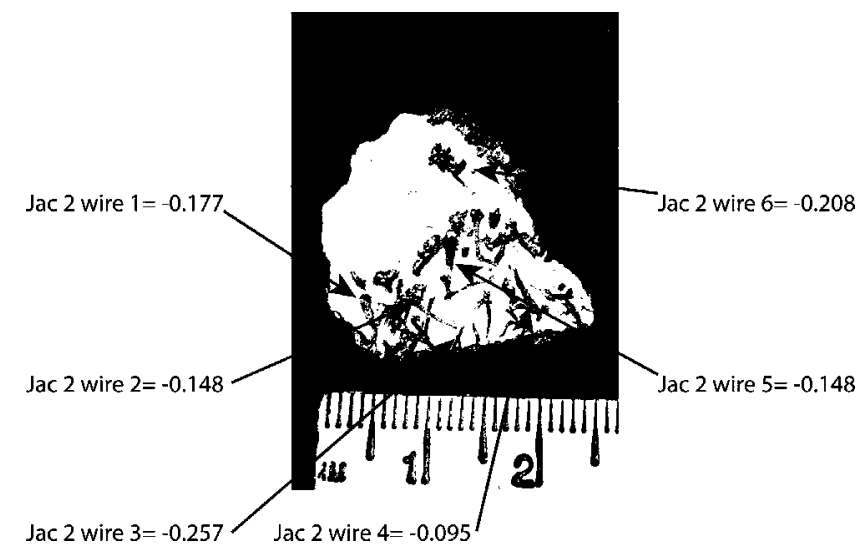

Fig. 3. Sample locations for 6 wires pulled from a JAC-2. Each wire location has a $\delta^{109} \mathrm{Ag}$ in per mil units labeled. The variation of Ag isotope composition with this set of wires in on the order of 0.05 permil.

the measuring session, and the ion exchange chromatography eliminated the $\mathrm{Zr}$ from the analyzed solution.

Forty ratios were collected and on-peak blanks were subtracted out of each measurement. Background ${ }^{107} \mathrm{Ag}$ ranged from 0.4 to $1 \mathrm{mV}$. Samples and standards were kept to within $20 \%$ concentration, although as seen in Fig. $2 \mathrm{~B}$, variation of the sample (CM $188=0.14)$ concentration in comparison to the standard does not appear to generate different isotope values within a range of $\pm 4 \mathrm{~V}$. The NIST silver isotope standard 978 was used as the bracketing standard. Previous studies have provided epsilon values $(\varepsilon)$, which are one order of magnitude greater than the traditional per mil format defined here as:

$\delta^{109} \mathrm{Ag} \%=\left(\frac{\left(\frac{109_{A g}}{107_{A g}}\right) \text { sample }}{\left(\frac{109_{A g}}{107_{A g}}\right) \text { NIST978 }}-1\right) * 1000$

\subsubsection{Errors for Ag isotope measurements}

Errors for each measurement were assessed several ways. The overall measurement errors were consistently within the fourth decimal place, this error most likely greatly underestimates the total error of the process. The whole procedural blank is $<0.8$ nanograms and does not impact the measurements that are occurring in solutions at 3 orders of magnitude larger. The standard compared to itself throughout three analytical sessions produces a $2 \sigma=0.015, \mathrm{n}=48$. Duplicate measurements all fall within this range of error and this appears to be a robust error for these measurements. Sample CM191 was taken through the separation procedure five times and produced the value $0.065 \%$ reported in Table 1 and has a $2 \sigma$ of $0.012 \%$.

One sample (JAC-2 wire, Fig. 3) shows multiple silver wires which were sampled individually for silver isotope analysis. As displayed in the figure, measurable and significant variation of the silver isotope composition exists within the same specimen where 6 different wires plucked from the same sample have a mean $\delta^{109} \mathrm{Ag}=-0.17 \pm$ $0.05 \%(1 \sigma)$. The error calculated here most likely represents the error within a sample that contains multiple wires of silver and could relate to the isotopic variations found within specimens. In contrast, the analytical error of chemical separation and measurement is less and considered to be $0.015 \%$.

\subsection{Scanning Electron Microscope (SEM) imaging and energy dispersive X-ray spectroscopy (EDS) measurements}

To further investigate how the silver was adsorbed onto the mineral, imaging of the $\mathrm{MnO}_{2}$ surface and chemical analysis of the grains were conducted. The native silver and silver sulfide samples were dried and carbon coated. The residual $\mathrm{MnO}_{2}$ minerals were filtered and rinsed with MQ water and dried. Double-sided carbon tape was pasted onto a thin section slide and the $\mathrm{MnO}_{2}$ grains were carefully sprinkled on the tape. The slide was carbon coated and loaded into the SEM at Juniata College. The images were taken in back-scattered mode to enhance phase contrast. The signal was set at $20 \mathrm{kV}$, a working distance of 10 $\mathrm{mm}$, and the EDS was normalized with a Co standard. At least 20 grains were chemically analyzed from each of the $\mathrm{pH}$ ranges of the experiments by point and map analysis. The typical error using the virtual synthetic standards for analysis of all elements reported is on the order of $0.5 \%$. Due to spherical nature of the surfaces, exact concentration data are not reported, rather the presence of the spectra were used to confirm elements present.

\subsection{Fractionation factor and mass balance calculations}

Due to the fact that the concentration and isotope value for the silver are known (or easily solved for as described for the $\mathrm{MnO}_{2}$ experiments) for the experiments conducted both $\Delta_{\text {aq-min }}$ and the fractionation factor $\alpha_{\text {aq-min }}$ can be calculated (Faure, 1986) where the following expressions are used:

$\Delta_{\text {aq-minl }}=\delta^{109} \mathrm{Ag}_{\mathrm{aq}}-\delta^{109} \mathrm{Ag}_{\text {min }}$

$\alpha_{\text {aq-min }}=\left(\delta^{109} \mathrm{Ag}_{\mathrm{aq}}+1000\right) /\left(\delta^{109} \mathrm{Ag}_{\min }+1000\right)$

where $\mathrm{aq}=$ aqueous solutions and $\min =$ mineral. These values, and the data used to calculate them are in Table 1. The $\delta^{109} \mathrm{Ag}_{\min }$ of the residual $\mathrm{MnO}_{2}$ was inhibited by the 
inability to completely dissolve the material in the ADS + PPT experiments, thus the $\delta^{109} \mathrm{Ag}_{\text {min }}$ of the $\mathrm{MnO}_{2}$ can be calculated using the following mass balance expression for the ADS + PPT experiments:

$\delta^{109} \mathrm{Ag}_{\text {nist978 }} \mathrm{f}_{\text {nist978 }}=\delta^{109} \mathrm{Ag}_{\mathrm{aq}} \mathrm{f}_{\mathrm{aq}}+\delta^{109} \mathrm{Ag}_{\min } \mathrm{f}_{\text {min }}$

where $f=$ the ratio of the mass of silver in the phase of interest divided by the total mass of silver in the starting material. This expression checks the consistency of the observations made and is further discussed later in this paper.

Due to the removal of a volume of fluid for the isotope analysis in the ADS experiments, the mass balance equation must account for this loss of silver from the system.

$$
\begin{aligned}
\delta^{109} \mathrm{Ag}_{\text {leach }} \mathrm{f}_{\text {leach }}= & \delta^{109} \mathrm{Ag}_{\mathrm{aq}} \mathrm{f}_{\text {aq }}+\delta^{109} \mathrm{Ag}_{\text {min }} \mathrm{f}_{\text {min }} \\
& -\delta^{109} \mathrm{Ag}_{\text {aq removed }} \mathrm{f}_{\text {aq removed }}
\end{aligned}
$$

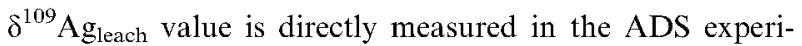
ments by leaching the $\mathrm{MnO}_{2}$ and $\mathrm{FeOOH}$ minerals post experiment with a $\mathrm{pH}=1$ nitric acid solution. This value is labeled Total in Table 4. Eq. (5) can be solved for the $\delta^{109} \mathrm{Ag}_{\min } \mathrm{f}_{\text {min }}$ which in turn can be substituted in Eq. (4) and the mass balance can be solved. The value solved for this expression should be within error of the standard, which is $0 \pm 0.015 \%$.

\section{RESULTS}

\subsection{Leach experiments}

For the native silver experiment, the leach solution has a $\delta^{109} \mathrm{Ag}$ value greater than the starting material. However, the residual material did not change $\delta^{109} \mathrm{Ag}$ min within reported errors. Approximately $8 \%$ of the total mass of the silver leached into solution (Table 3). The heavier isotope apparently releases into solution preferentially during oxidation of native silver.

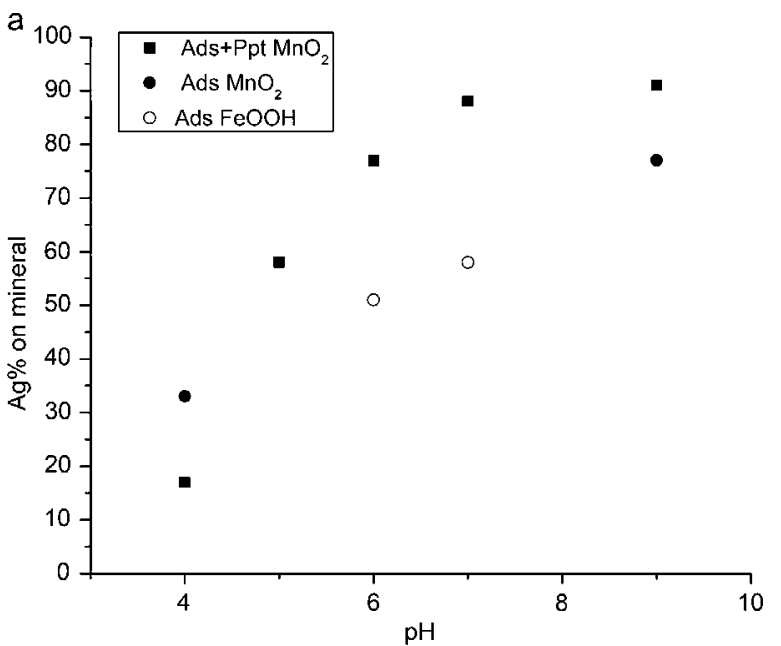

In contrast, for the $\mathrm{Ag}_{2} \mathrm{~S}$ experiment, the leach solution has the same $\delta^{109} \mathrm{Ag}$ value as the starting and ending mineral. Only $3 \%$ of the silver was leached into solution for this experiment. No measurable fractionation occurred during this experiment thus the fractionation factor is 1 .

No phase differences were detected in the SEM analysis of the surface of these mineral grains.

\subsection{Precipitation and sorption of silver onto $\mathrm{MnO}_{2}$}

Silver adsorbed and precipitated onto the $\mathrm{MnO}_{2}$ in various amounts, which was controlled by the $\mathrm{pH}$ of the solution in both experiment types. At low $\mathrm{pH}$, less silver was adsorbed or precipitated on the mineral surfaces. As seen in Fig. 4A for the ADS + PPPT, the amount of silver on the mineral surface increases with increasing $\mathrm{pH}$. The adsorption of metal onto $\mathrm{Mn}$ oxide phases is well-studied (Keller and Domergue, 1996; Weber et al., 2009) and in this instance the Langmuir equation (used to model adsorption) is the best of the three traditional models for both ADS + PPT experiments because the $\mathrm{r}^{2}=0.98$ and KI calculated capacity for the $\mathrm{MnO}_{2}$ in these experiments is $0.67 \mathrm{~L} / \mathrm{mg}$. For the ADS experiments (Fig. 4A), the pH also controlled the amount of adsorption of metal onto the surface, but did not display as convincing Langmuir behavior because the $\mathrm{r}^{2}=0.78$. SEM images as seen in Fig. 5 were used to determine adsorption and/or precipitation of silver on the mineral surface. Precipitation of silver is evident when native silver was detected on the surface. In contrast, when no native silver was found on the surface, but silver lines were present when measuring post MnOxide grain, silver was adsorbed to the surface.

The silver isotope value of the solution varies significantly for different $\mathrm{pH}$ values for the ADS + PPT experiments (Fig. 4B) and all solutions have values that are larger than the starting NIST 978 value of $0 \%$. Calculated fractionation factors $\left(\alpha_{\mathrm{aq}-\mathrm{minl}}\right)$ remain relatively constant for $\mathrm{pH} 5,6$, and 7 . The same constant fractionation factor

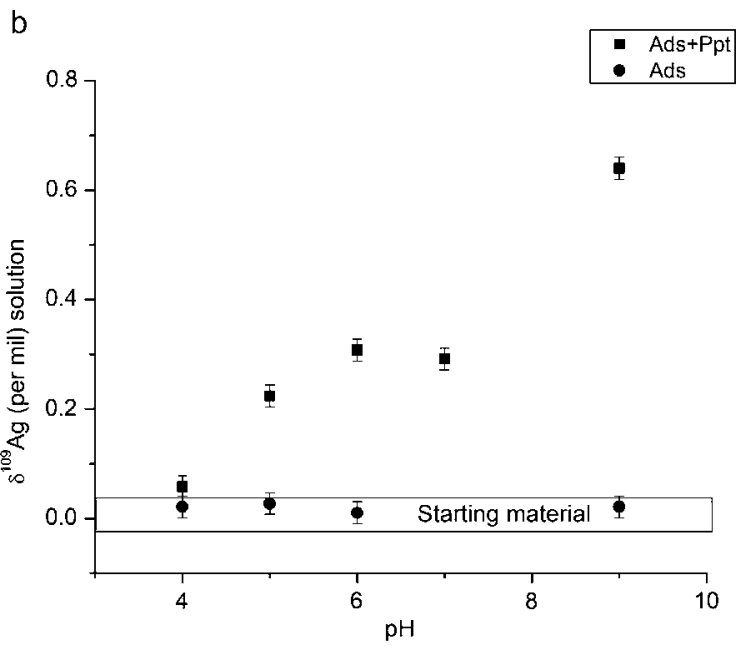

Fig. 4. The figures show how silver adsorbed onto the mineral grains (A) and (B) that the lighter silver isotope was favored in the precipitant or absorbed metal. 


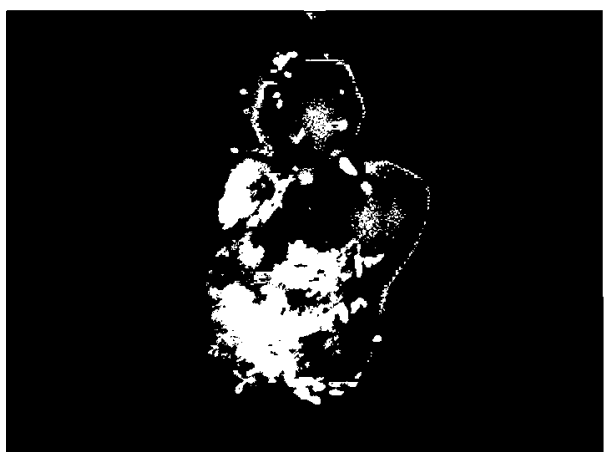

Electron Image 1

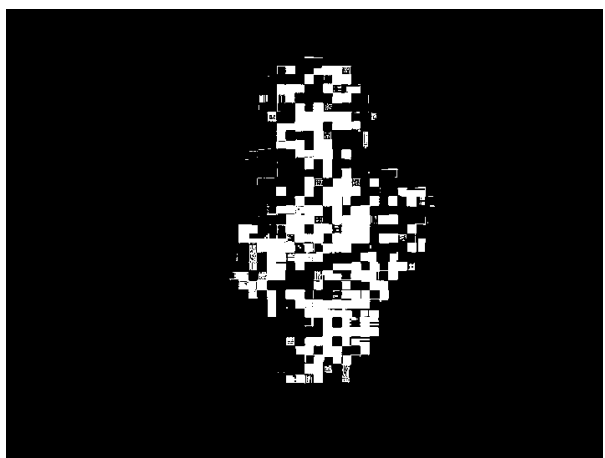

$M \cap K a 1$

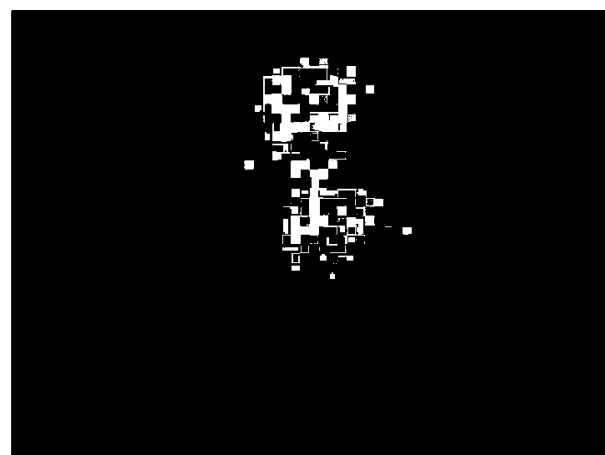

OKa1

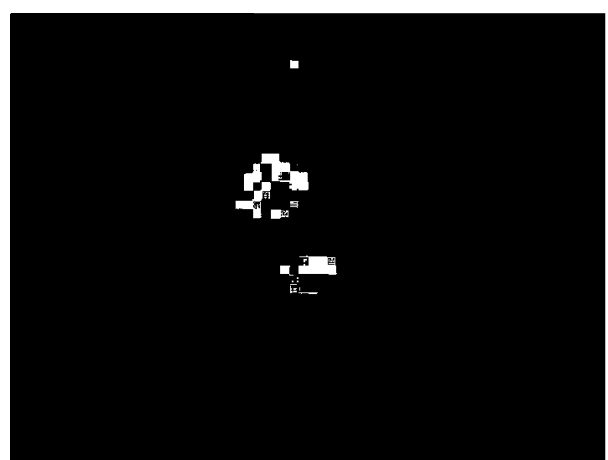

Ag La1

Fig. 5. SEM image with EDS spectra maps from $\mathrm{MnO}_{2} \mathrm{pH} 8$ experiment which shows native silver precipitants on the $\mathrm{MnO}_{2}$ mineral surface.

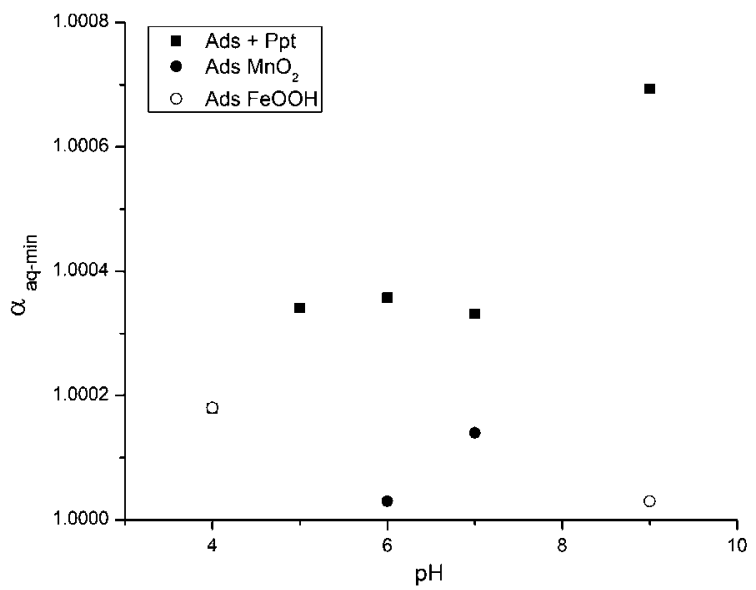

Fig. 6. Comparison of the fractionation factor measured over the range of $\mathrm{pH}$ and different mineral that adsorbed silver. Note that precipitation reactions generate larger degrees of fractionation and that $\mathrm{pH}$ does exert some control on the fractionation factors.

due to adsorption of molybdenum onto $\mathrm{MnO}_{2}$ was reported for near neutral $\mathrm{pH}$ surface solutions (Anbar et al., 2004; Barling and Anbar, 2004). In contrast, at the lowest $\mathrm{pH}$ the fractionation factor is the lowest and at the highest $\mathrm{pH}$ the fractionation factor is at the highest value (Fig. 6).

The $\mathrm{Ag}$ isotope value of the solution does not change significantly for the ADS experiments with $\mathrm{MnO}_{2}$ and
FeOOH in the range of $5-9 \mathrm{pH}$ units (Fig. 4B). Calculated fractionation factors $\left(\alpha_{\mathrm{aq}-\mathrm{minl}}\right)$ remain very close to 1 for the experiments at pH 6 and 9 (Fig. 6). Mass balance calculations for the ADS experiments all fall within the measurement errors.

Mineral phases did not show significant differences in these experiments. In fact, $\mathrm{FeOOH}$ and $\mathrm{MnO}_{2}$ experiments at $\mathrm{pH} 4$ yielded identical fractionation factors in the ADS + PPT and ADS experiments, while the $\mathrm{pH} 9 \mathrm{FeOOH}$ and $\mathrm{pH} 5,6,8 \mathrm{MnO}_{2}$ experiments have identical fractionation factors.

SEM images with EDS spectra reveal that silver adsorbed onto the $\mathrm{MnO}_{2}$ used in both experiments. Grains in each experiment had spectral silver lines and concentrations on the $\mathrm{MnO}_{2}$ surface $>1 \%$. In the experiments exposed to light, native silver precipitated on the surfaces of the $\mathrm{MnO}_{2}$. As seen in Fig. 5, the element map shows areas of high concentration that lack oxygen and manganese, thus the lightest color phase is native silver. Submicron flecks of native silver were present in all $\mathrm{MnO}_{2}$ from the range of $\mathrm{pH}$ examined, however the larger crystals of native silver $(>5 \mu \mathrm{m})$ as shown in Fig. 5 were restricted in $\mathrm{pH} 7$ and $\mathrm{pH} 9 \mathrm{MnO}_{2}$. Point and ID EDS spectra on $\mathrm{MnO}_{2}$ not displaying abundant native silver, possess anywhere from 1 to $1.8 \% \mathrm{Ag}$. This is evidence that not only did the surface of $\mathrm{MnO}_{2}$ promote precipitation of native silver, but no free bound silver phases were detected in the experiments. Thus, all silver metal appears to be associated within or on the surface of the $\mathrm{MnO}_{2}$ for all experiments. 


\subsection{Ore deposit native silver experiments}

The $\delta^{109} \mathrm{Ag}$ values for natural native silver from worldwide ore deposits ranged from +2.1 to $-0.86 \%$, a $2.9 \%$ spread of values (Table 2). Native silver from high temperature mineralization tends to cluster around 0 per mil with an average value of $+0.05 \pm 0.1 \%$ o $(1 \sigma)$. In contrast, the native silver from lower temperature mineralization overlaps and flanks the mean high temperature native silver isotope values. These reported values expand the known fractionation of published silver isotope in native silver values by $1 \%$.

\section{DISCUSSION}

\subsection{Fractionation of silver during leaching of silver minerals}

The goal of these two experiments was to compare reactions that involved the oxidation of silver into solution (leaching of native $\mathrm{Ag}$ ) and the release of silver into solution without electron transfer (leaching of $\mathrm{AgS}_{2}$ ). As shown in Table 2, oxidation of $\mathrm{Ag}$ to $\mathrm{Ag}+$ in the native experiments produced a solution that is isotopically heavier than the starting material. In contrast, dissolution of silver without a redox shift does not produce differences between the isotopic composition of the solution and the starting material. As no extraneous minerals were observed on the mineral surfaces, no other geochemical reactions involving different mineral phases could explain the reactions in these experiments. Thus, the oxidation of silver favors the heavier isotope during dissolution.

Redox reactions in the geological environment cause isotopic fractionation in several transition metal isotopes. The oxidative environment favors the heavier isotope in multiple different geochemical reactions involving electron transfer for $\mathrm{Fe}, \mathrm{Cu}, \mathrm{Zn}, \mathrm{Mo}, \mathrm{Cd}$, and $\mathrm{Sn}$ (Beard et al., 2003; Johnson, 2004; Ehrlich et al., 2004; Kavner et al., 2005; Cloquet et al., 2006; Markl et al., 2006; Wille et al., 2007; Domagal-Goldman and Kubicki, 2008; Kavner et al., 2008; Bigalke et al., 2009; Dauphas et al., 2009; Black et al., 2010; Asael et al., 2012; Chrastný et al., 2015). For the oxidation of silver from native silver, the degree $(0.06 \mathrm{amu})$ of fractionation is smaller than reported for the other metal isotopes. This could be related to the fact the dissolution is a simple system while the other isotopic systems have modeled more complex reactions like those discussed below such as adsorption and precipitation. Regardless, the degree of fractionation reported here is much greater than the error of the measurement and could potentially be one of several causes for $\mathrm{Ag}$ isotope fractionation in nature.

\subsection{Mass balance for the adsorption experiments}

Mass balance for all chemical components must exist in order for any mechanisms of fractionation to be considered. The only limiting factor in constraining mass balance in the set of experiments conducted is calculation and measurement of the adsorbed and/or precipitated $\mathrm{Ag}$ on the $\mathrm{MnO}_{2}$ and $\mathrm{FeOOH}$ mineral surface. The reason for compli- cations in these experiments is the isolation of all the finegrained minerals used for analysis. Nonetheless, for the ADS + PPT experiments, in order for mass balance to be achieved the silver isotope composition of the surface was calculated and is presented in Table 4.

To better constrain this value, in the ADS experiments, the residual mineral surfaces were leached with nitric acid to release silver into solution. The remaining leach solution was then used to further constrain the silver isotopic composition of the adsorbed metal. As seen in Table 4, the mass balance is achieved within error for the four experiments presented. This indicates that the silver in the experiments occurs on the surface or in solution and further corroborates the SEM imagery that shows no other Ag-rich phases cause the fractionation of silver recorded in the experiments.

\subsection{Silver isotopic fractionation induced by adsorption versus precipitation}

The two experiments allow for comparison of adsorption or precipitation of silver onto the mineral surface. As shown in Fig. 6, in the experiments where just adsorption occurred, the magnitude of fractionation $\left(\Delta_{\text {aq-minl }}, \alpha_{\text {aq-minl }}\right)$ is in the same direction but significantly less than that seen in the ADS + PPT experiments. The magnitude of fractionation also seemed to decrease with increasing $\mathrm{pH}$ due to adsorption, whereas the ADS + PPT the magnitude increased with increasing $\mathrm{pH}$.

Clearly, in the ADS + PPT experiments, the reduction of native silver onto the surface accounts for the larger degree of fractionation. As seen in the leach experiments, a redox reaction causes the fractionation of the isotopes, which is the major difference between the two experiments. The magnitude of fractionation is also higher than recorded in the leaching oxidation experiments for $\mathrm{pH}>5$. Equally important is the fact that at a pH of 4 or less in the ADS + PPPT, Ads, and leach experiments the $\left(\Delta_{\text {aq-min1 }}, \alpha_{\text {aq-minl }}\right)$ are nearly identical. These observations point to the fact that both redox and $\mathrm{pH}$ exert control on the degree of fractionation of silver in these experiments. The rationale behind these trends mostly likely stems from the fact that more native $\mathrm{Ag}$ precipitated at higher $\mathrm{pH}$ levels and the redox reaction tends to cause a greater degree of separation between the isotopes.

The $\Delta_{\text {aq-minl }}$, and $\alpha_{\text {aq-minl }}$ for the ADS experiments is in the same direction as seen for copper (Balistrieri et al., 2008; Liu et al., 2014), molybdenum (Barling and Anbar, 2004) and cadmium (Wasylenki et al., 2014). The set of experiments here did not test variations due to large changes in ionic strength, differing types of $\mathrm{MnO}_{2}$, and other geochemical variables presented for the other isotope systems cited. The data do provide a first order understanding of fractionation induced by adsorption of silver. However, the large degree of fractionation recorded in the ADS + PPT and leach experiments indicate that redox reactions in nature may mask ability to link silver isotope fractionation to solely adsorption. For instance, the molybdenum isotope composition in seawater is controlled by adsorption reactions that happen on $\mathrm{Fe}-\mathrm{Mn}$ oxides 


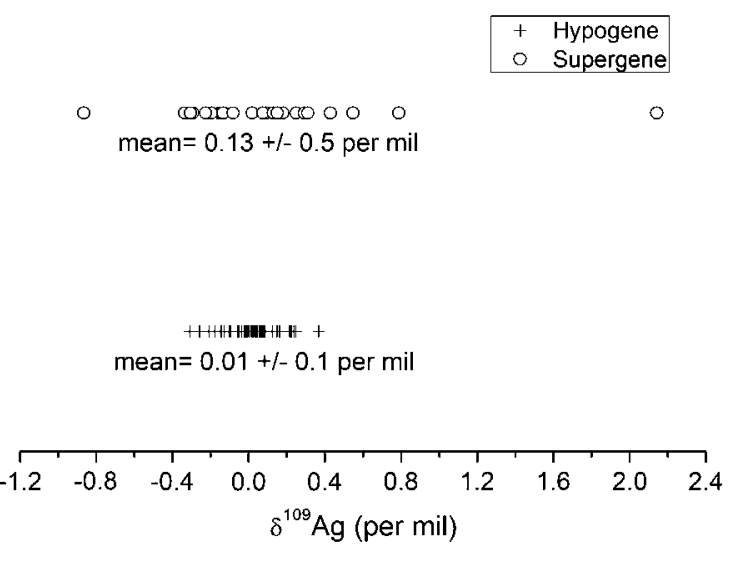

Fig. 7. Comparison of the $\delta^{109} \mathrm{Ag}$ values for hypogene and supergene native silver specimens from around the world.

(Anbar et al., 2004; Arnold et al., 2004), but the same argument could not be made for the silver results presented here.

\subsection{Silver isotope variations in native silver from natural systems}

Previous studies have shown that the range of silver isotope compositions in native silver range about $0 \pm 0.2 \%$ (Schönbächler et al., 2007; Yang et al., 2009; Desaulty et al., 2011), with larger silver isotope ranges measured in native gold (Chugaev and Chernyshev, 2012) and chondrites (Schönbächler et al., 2008). The presented data greatly expand the known isotopic range for native silver and illustrates that the ranges could be related to basic geologic process and perhaps used for sourcing artifacts with greater clarity.

No systematic silver isotope range appears to exist for a specific type of silver deposit, nor for a specific geographic region (Table 1). The range of over $0.4 \%$ within a specific location indicates a detailed study of one deposit may be needed to see systematic variations in $\mathrm{Ag}$ isotope compositions in ores. For instance, both copper and molybdenum isotope systems have documented isotopic patterns in ores that formed closer to the source of hydrothermal activity in comparison to ores that formed in distal parts of the systems. These types of systematic isotope variations in proximal and distal ores have been seen in other transition metal isotopes (Mathur et al., 2009; Shafiei et al., 2015).

The hypogene data form a tight cluster which the supergene data overlies and flanks Fig. 7. Deposits that formed by high temperature mineralization processes (termed hypogene mineralization) have values that cluster around $0 \%$. The supergene samples overlap this range. The supergene deposits have had some secondary reconstitution of silver that happened at lower temperatures $\left(<150^{\circ} \mathrm{C}\right)$. Silver from the large copper deposits in Michigan has a homogenous silver signature throughout five different samples. This is the most consistent result obtained and the copper isotope compositions in the same native copper specimens are relatively uniform from this area (Larson et al., 2003; Mathur et al., 2014). Perhaps an annealing process during regional metamorphic events or the development of a homogeneous isotopic signature during the fluids flow events related to mineralization caused this consistent isotopic signature.

Most of the deposits analyzed possess silver present in multiple redox states in different ore minerals and are surrounded by $\mathrm{MnO}_{2}$ haloes. The isotopic variability presented here from the secondary ores could be related to the redox reactions or adsorption processes described here. Thus, the experimental work provides mechanisms that could explain the variation of silver isotopic values in native silver. As pointed out above, more detailed sampling with different silver phases throughout one system is needed. The mobilization of silver at low (ambient) temperature and formation of supergene enrichment is debatable in some of the deposits, so clearer studies of single deposits will help determine if these supergene processes are important in the concentration of silver in the crust.

\section{CONCLUSIONS}

Significant silver isotope fractionation occurs in native silver isotope samples from a range of deposits and interpreted origins. Silver isotope fractionation presented in the experimental work supports the degree of silver isotope fractionation found in natural samples can be explained by redox and adsorption reactions. The degree and magnitude of silver isotope fractionation presented here is in line with other transition metal isotopes.

Specifically, the technique could be used to identify low temperature remobilization during supergene weathering of a deposit. Equally significant, the data point to the ability to trace metals that were scavenged and migrated through materials. For instance, the effectiveness of metal remediation by different medium could be compared and explained. These data clearly point to the value for more detailed studies that silver isotope compositions in ores and widens the range for using silver isotopes in environmental and hydrometallugical applications.

\section{ACKNOWLEDGEMENTS}

We would like to thank C. Gammons for his insight comments regarding experimentation setup and design. The presentation and clarity of the document was greatly improved by the commentary of three anonymous reviewers and the editor E. Ripley. We would also like to thank Akita University for funding the experimentation and measurements. Samples for study were kindly provided by Dr. Osamu Nishikawa (Akita University), Dr. Joan Carles Melgarejo Draper (University of Barcelona), Dr. Marc Campeny Crego (Natural History Museum of Barcelona), Christian Peña Narciso (Madrid School of Mines) and Mr. Joan Abello iCreus. Finally, we would like to thank M. Gonzalez for aid in instrumentation and method setup on the Neptune mass spectrometer.

\section{APPENDIX A. SUPPLEMENTARY MATERIAL}

Supplementary data associated with this article can be found, in the online version, at https://doi.org/10.1016/j. gca.2018.01.011. 


\section{REFERENCES}

Anbar A. D., Roe J. E., Anbar A. D. and Barling J. (2004) Molybdenum stable isotopes: observations, interpretations and directions nonbiological fractionation of Fe isotopes; evidence of an equilibrium isotope effect. Rev. Mineral. Geochem. 55, $429-454$.

Anbar A. D., Roe J. E., Barling J. and Nealson K. H. (2000) Nonbiological fractionation of iron isotopes. Science 288, 126 128.

Anderson B. J., Jenne E. A. and Chao T. T. (1973) The sorption of silver by poorly crystallized manganese oxides. Geochim. Cosmochim. Acta 37, 611-622.

Arnold G. L., Anbar A. D., Barling J. and Lyons T. W. (2004) Molybdenum isotope evidence for widespread anoxia in midProterozoic oceans. Science 304, 87-90.

Asael D., Matthews A., Bar-Matthews M., Harlavan Y. and Segal I. (2012) Tracking redox controls and sources of sedimentary mineralization using copper and lead isotopes. Chem. Geol. 310-311, 23-35.

Balistrieri L. S., Borrok D. M., Wanty R. B. and Ridley W. I. (2008) Fractionation of $\mathrm{Cu}$ and $\mathrm{Zn}$ isotopes during adsorption onto amorphous $\mathrm{Fe}$ (III) oxyhydroxide: Experimental mixing of acid rock drainage and ambient river water. Geochim. Cosmochim. Acta 72, 311-328.

Barling J. and Anbar A. D. (2004) Molybdenum isotope fractionation during adsorption by manganese oxides. Earth Planet. Sci. Lett. 217, 315-329.

Beard B. L., Johnson C. M., Von Damm K. L., Poulson R. L., Croal L. R. and Newman D. K. (2003) Iron isotope constraints on Fe cycling and mass balance in oxygenated Earth oceans Iron isotope fractionation by $\mathrm{Fe}(\mathrm{II})$-oxidizing photoautotrophic bacteria. Geology 31, 629-632.

Bigalke M., Weyer S. and Wilcke W. (2009) Stable copper isotopes: a novel tool to trace copper behavior in hydromorphic soils. Soil. Sci. Soc. Am. J. 74, 60-73.

Bigalke M., Weyer S. and Wilcke W. (2011) Stable Cu isotope fractionation in soils during oxic weathering and podzolization. Geochim. Cosmochim. Acta 75, 3119-3134.

Black J. R., Young E. D. and Kavner A. (2010) Electrochemically controlled iron isotope fractionation. Geochim. Cosmochim. Acta 74, 809-817.

Bodnar R., Lecumberri-Sanchez P., Moncada D. and SteeleMacInnis M. (2014) Fluid inclusions in hydrothermal ore deposits.

Carlson R. W. and Hauri E. H. (2001) Extending the 107Pd-107Ag chronometer to low $\mathrm{Pd} / \mathrm{Ag}$ meteorites with multicollector plasma-ionization mass spectrometry. Geochim. Cosmochim. Acta 65, 1839-1848.

Chrastný V., Cadková E., Vaněk A., Teper L., Cabala J. and Komárek M. (2015) Cadmium isotope fractionation within the soil profile complicates source identification in relation to $\mathrm{Pb}-$ $\mathrm{Zn}$ mining and smelting processes. Chem. Geol. 405, 1-9.

Chugaev A. and Chernyshev I. (2012) High-noble measurement of $107 \mathrm{Ag} / 109 \mathrm{Ag}$ in native silver and gold by multicollector inductively coupled plasma mass spectrometry (MC-ICP-MS). Geochem. Int. 50, 899-910.

Cloquet C., Carignan J., Libourel G., Sterckeman T. and Perdrix E. (2006) Tracing source pollution in soils using cadmium and lead isotopes. Environ. Sci. Technol. 40, 2525-2530.

Dauphas N., Craddock P. R., Asimow P. D., Bennett V. C., Nutman A. P. and Ohnenstetter D. (2009) Iron isotopes may reveal the redox conditions of mantle melting from Archean to Present. Earth Planet. Sci. Lett. 288, 255-267.
Desaulty A.-M., Telouk P., Albalat E. and Albarède F. (2011) Isotopic $\mathrm{Ag}-\mathrm{Cu}-\mathrm{Pb}$ record of silver circulation through 16 th18th century Spain. Proc. Natl. Acad. Sci. 108, 9002-9007.

Domagal-Goldman S. D. and Kubicki J. D. (2008) Density functional theory predictions of equilibrium isotope fractionation of iron due to redox changes and organic complexation. Geochim. Cosmochim. Acta 72, 5201-5216.

Drever J. I. (1988) The geochemistry of natural waters. Prentice Hall Englewood Cliffs.

Ehrlich S., Butler I., Halicz L., Rickard D., Oldroyd A. and Matthews A. (2004) Experimental study of the copper isotope fractionation between aqueous $\mathrm{Cu}$ (II) and covellite, $\mathrm{CuS}$. Chem. Geol. 209, 259-269.

Ek M., Hunt A. C. and Schonbachler M. (2017) A new method for high-precision palladium isotope analyses of iron meteorites and other metal samples. J. Anal. At. Spectrom. 32, 647-656.

Faure, G. (1986). John Wiley \& Sons, New York, NY.

Graybeal F. and Vikre P. (2010) A review of silver-rich mineral deposits and their metallogeny: Society of Economic Geologists. Special Publication 15, 85-117.

Horner T. J., Schönbächler M., Rehkämper M., Nielsen S. G., Williams H., Halliday A. N., Xue Z. and Hein J. R. (2010) Ferromanganese crusts as archives of deep water $\mathrm{Cd}$ isotope compositions. Geochem., Geophys., Geosyst. 11, n/a-n/a.

Jang J.-H., Mathur R., Liermann L. J., Ruebush S. and Brantley S. L. (2008) An iron isotope signature related to electron transfer between aqueous ferrous iron and goethite. Chem. Geol. 250, $40-48$.

Johnson T. M. (2004) A review of mass-dependent fractionation of selenium isotopes and implications for other heavy stable isotopes. Chem. Geol. 204, 201-214.

Kavner A., Bonet F., Shahar A., Simon J. and Young E. (2005) The isotopic effects of electron transfer: An explanation for $\mathrm{Fe}$ isotope fractionation in nature. Geochim. Cosmochim. Acta 69 , 2971-2979.

Kavner A., John S. G., Sass S. and Boyle E. A. (2008) Redoxdriven stable isotope fractionation in transition metals: Application to $\mathrm{Zn}$ electroplating. Geochim. Cosmochim. Acta 72, $1731-1741$.

Keller C. and Domergue F.-L. (1996) Soluble and particulate transfers of $\mathrm{Cu}, \mathrm{Cd}, \mathrm{Al}, \mathrm{Fe}$ and some major elements in gravitational waters of a Podzol. Geoderma 71, 263-274.

Kesler S. E. and Simon A. C. (2015) Mineral Resources, Economics and the Environment. Cambridge University Press.

Larson L. T. (1964) Geology and mineralogy of certain manganese oxide deposits. Econ. Geol. 59, 54-78.

Larson P. B., Maher K., Ramos F. C., Chang Z., Gaspar M. and Meinert L. D. (2003) Copper isotope ratios in magmatic and hydrothermal ore-forming environments. Chem. Geol. 201, $337-350$.

Little S. H., Vance D., Walker-Brown C. and Landing W. M. (2014) The oceanic mass balance of copper and zinc isotopes, investigated by analysis of their inputs, and outputs to ferromanganese oxide sediments. Geochim. Cosmochim. Acta 125, 673-693.

Liu S.-A., Teng F.-Z., Li S., Wei G.-J., Ma J.-L. and Li D. (2014) Copper and iron isotope fractionation during weathering and pedogenesis: Insights from saprolite profiles. Geochim. Cosmochim. Acta 146, 59-75.

Lu D., Liu Q., Zhang T., Cai Y., Yin Y. and Jiang G. (2016) Stable silver isotope fractionation in the natural transformation process of silver nanoparticles. Nat. Nanotechnol. 11, 682-686.

Luo Y., Dabek-Zlotorzynska E., Celo V., Muir D. C. and Yang L. (2010) Accurate and precise determination of silver isotope 
fractionation in environmental samples by multicollectorICPMS. Anal. Chem. 82, 3922-3928.

Markl G., Lahaye Y. and Schwinn G. (2006) Copper isotopes as monitors of redox processes in hydrothermal mineralization. Geochim. Cosmochim. Acta 70, 4215-4228.

Mathur R., Titley S., Barra F., Brantley S., Wilson M., Phillips A., Munizaga F., Maksaev V., Vervoort J. and Hart G. (2009) Exploration potential of $\mathrm{Cu}$ isotope fractionation in porphyry copper deposits. J. Geochem. Explor. 102, 1-6.

Mathur R., Wilson M. and Parra M. L. (2014) Challenges of using copper isotope ratios to trace the origin of native copper artifacts: an example from the Keweenaw Peninsula. Ann. Carnegie Museum 82, 241-245.

McKenzie R. (1980) The adsorption of lead and other heavy metals on oxides of manganese and iron. Soil Res. 18, 61-73.

Megaw P. K. (1998) Carbonate-hosted Pb-Zn-Ag-Cu-Au replacement deposits: an exploration perspective. Mineralized intrusion-related skarn systems: Mineralogical Association of Canada Short Course Notes 26, 337-357.

Nicholson K. (1992) Contrasting mineralogical-geochemical signatures of manganese oxides; guides to metallogenesis. Econ. Geol. 87, 1253-1264.

Pokrovsky O. S., Viers J., Emnova E. E., Kompantseva E. I. and Freydier R. (2008) Copper isotope fractionation during its interaction with soil and aquatic microorganisms and metal oxy (hydr)oxides; possible structural control. Geochim. Cosmochim. Acta 72, 1742-1757.

Poulson R. L., Johnson C. M., Beard B. L., Croal L. R., Johnson C., Beard B., Welsch S., Poulson R. and Newman D. K. Anonymous (2005) Iron isotope exchange kinetics at the nanoparticulate ferrihydrite surface. Development of an iron isotope biosignature for anaerobic photosynthetic Fe(II) oxidizing bacteria. Am. Mineral. 90, 758-763.

Schauble E. A., Rossman G. R. and Taylor H. P. (2001) Theoretical estimates of equilibrium Fe-isotope fractionations from vibrational spectroscopy. Geochim. Cosmochim. Acta 65, 2487-2497.

Schmitt A.-D., Galer S. J. G. and Abouchami W. (2009) Massdependent cadmium isotopic variations in nature with emphasis on the marine environment. Earth Planet. Sci. Lett. 277, 262 272.

Schönbächler M., Carlson R. W., Horan M. F., Mock T. D. and Hauri E. H. (2007) High precision Ag isotope measurements in geologic materials by multiple-collector ICPMS: an evaluation of dry versus wet plasma. Int. J. Mass Spectrom. 261, 183-191.
Schönbächler M., Carlson R. W., Horan M. F., Mock T. D. and Hauri E. H. (2008) Silver isotope variations in chondrites: Volatile depletion and the initial 107Pd abundance of the solar system. Geochim. Cosmochim. Acta 72, 5330-5341.

Shafiei B., Shamanian G., Mathur R. and Mirnejad H. (2015) Mo isotope fractionation during hydrothermal evolution of porphyry Cu systems. Miner Deposita 50, 281-291.

Skulan J. L., Beard B. L. and Johnson C. M. (2002) Kinetic and equilibrium $\mathrm{Fe}$ isotope fractionation between aqueous $\mathrm{Fe}$ (III) and hematite. Geochim. Cosmochim. Acta 66, 2995-3015.

Sorem R. K. and Cameron E. N. (1960) Manganese oxides and associated minerals of the Nsuta manganese deposits, Ghana, West Africa. Econ. Geol. 55, 278-310.

Wasylenki L. E., Swihart J. W. and Romaniello S. J. (2014) Cadmium isotope fractionation during adsorption to $\mathrm{Mn}$ oxyhydroxide at low and high ionic strength. Geochim. Cosmochim. Acta 140, 212-226.

Weber F.-A., Voegelin A. and Kretzschmar R. (2009) Multi-metal contaminant dynamics in temporarily flooded soil under sulfate limitation. Geochim. Cosmochim. Acta 73, 5513-5527.

Wille M., Kramers J. D., Naegler T. F., Beukes N. J., Schroeder S., Meisel T., Lacassie J. P. and Voegelin A. R. (2007) Evidence for a gradual rise of oxygen between 2.6 and $2.5 \mathrm{Ga}$ from $\mathrm{Mo}$ isotopes and Re-PGE signatures in shales. Geochim. Cosmochim. Acta 71, 2417-2435.

Woodland S., Rehkämper M., Halliday A., Lee D.-C., Hattendorf B. and Günther D. (2005) Accurate measurement of silver isotopic compositions in geological materials including low $\mathrm{Pd}$ / Ag meteorites. Geochim. Cosmochim. Acta 69, 2153-2163.

Yang L., Dabek-Zlotorzynska E. and Celo V. (2009) High precision determination of silver isotope ratios in commercial products by MC-ICP-MS. J. Anal. At. Spectrom. 24, 1564 1569.

\section{FURTHER READING}

Du Laing G., Vanthuyne D. R. J., Vandecasteele B., Tack F. M. G and Verloo M. G. (1987) (2007) Influence of hydrological regime on pore water metal concentrations in a contaminated sediment-derived soil. Environ. Pollut. 147, 615-625. 